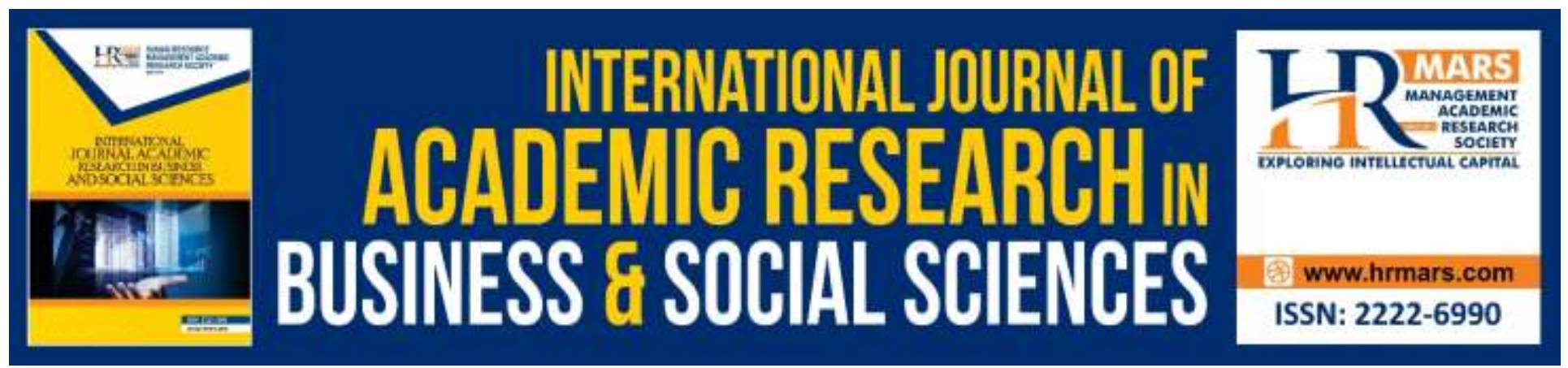

\title{
Romanians' Perception Regarding Cloud Services used on their Business Activities: Quantitative Research
}

\section{Anamaria-Catalina Radu, Andra-lleana Dobrescu}

To Link this Article: http://dx.doi.org/10.6007/IJARBSS/v10-i6/7332
DOI:10.6007/IJARBSS/v10-i6/7332

Received: 18 April 2020, Revised: 20 May 2020, Accepted: 09 June 2020

Published Online: 28 June 2020

In-Text Citation: (Radu, 2020)

To Cite this Article: Radu, A.-C. A.-I. D. (2020). Romanians' Perception Regarding Cloud Services used on their Business Activities: Quantitative Research. International Journal of Academic Research in Business and Social Sciences, 10(6), 560-571.

Copyright: (C) 2020 The Author(s)

Published by Human Resource Management Academic Research Society (www.hrmars.com) This article is published under the Creative Commons Attribution (CC BY 4.0) license. Anyone may reproduce, distribute, translate and create derivative works of this article (for both commercial and non-commercial purposes), subject to full attribution to the original publication and authors. The full terms of this license may be seen at: http://creativecommons.org/licences/by/4.0/legalcode

Vol. 10, No. 6, 2020, Pg. 560 - 571

Full Terms \& Conditions of access and use can be found at http://hrmars.com/index.php/pages/detail/publication-ethics 


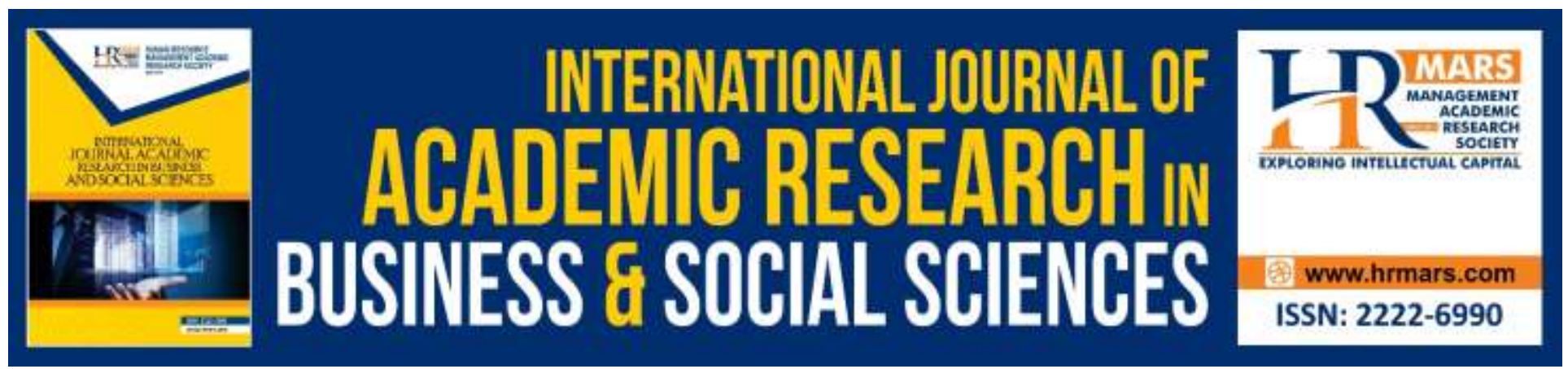

\title{
Romanians' Perception Regarding Cloud Services used on their Business Activities: Quantitative Research
}

\author{
Anamaria-Catalina Radu \\ Romanian Academy, Institute of National Economy, Bucharest, Romania. \\ Email: anamaria_radu15@yahoo.com \\ Andra-lleana Dobrescu \\ The Bucharest University of Economic Studies, Bucharest, Romania \\ Email: andra.dobrescu29@yahoo.com
}

\section{Abstract}

Technological developments in recent years have led to the rapid and continuous production of information, the management of which has become increasingly difficult even for companies. To carry out their daily activities, organisations began to need a large amount of data, which automatically led to the need to increase storage space. Cloud solutions have emerged as a solution to this problem, offering the possibility of storing a large amount of data. In this paper, we conducted a quantitative study through which we wanted to identify the perception of employees in Romania on the quality of cloud services that they use in the companies in which they work. The research was conducted on a sample of 315 respondents. Data were analysed using IBM SPSS Statistics 20.

Keywords: Cloud Computing, Services, Quantitative Research, Web Technologies.

\section{Introduction}

World Wide Web (WWW) is the largest database that mankind has invented, a database that allows queries with different syntax, returning results that can later be reused for various purposes. As the Internet evolves, it becomes more and more advanced, and the associated services and applications become more complex. The Internet has its origins in a 1970s project funded by the US Department of Defense. During that period, the first communication protocols began to emerge, as well as standardisations made by the International Organization for Standardization (ISO).

This is how the TCP/IP communication protocol for information transport was developed. In the 1980s, scientists realised that these technologies allowed access to large data libraries. It was not until the 1990s that the idea of unifying multiple local networks (intranets) into a large network called the Internet emerged to allow access to information for people in various geographical locations 
around the world (Thuraisingham, 2002, p.11). Currently, the Internet is seen as open to everyone and unrestricted (Passin, 2004, p.13).

The web has been used as a huge network of many subnets, which allows people to search, distribute and create digital files with information. Content distribution has been and will continue to be one of the most important aspects of the Internet (Tatntall, 2010, pp.22-23). It is known that the first generation of the Internet, generically called Web 1.0, revolutionised the world by connecting people from different geographical locations, by generating new learning opportunities for society (regardless of geographical location, religion, age, culture) by simply searching the Internet. The first generation of the Internet provided access to education for people who would not have had the opportunity to access that knowledge (Thuraisingham, 2002, pp.23).

Web 2.0, or "Social Web", allowed users to collaborate and share information using an open environment. This aspect is a distinctive feature of the social Web, being a collaboration between people through websites and applications, generically called "collective intelligence". One of the ways to classify content in Web 2.0 is by tagging, the user being allowed to attach text (links, keywords, bookmarks) before distributing the content. It is worth noting that these tags can be distributed, used in subsequent searches or recommended to other users who search the same content. A tag cloud is a visual representation of a user's tags, which are more or less important, depending on user preferences and the number of tags (O'Reilly, 2009).

The Web 3.0 generation focuses on identifying the meaning of information found in both humans and computers, generating an interconnectivity between them. Given the fact that the Web is expanding rapidly, there is a need to organise and manage it. One of the pressing issues of the Internet is the user's overloading with often unneeded information. Today, search engines, although greatly improved, still return inaccurate results, sometimes irrelevant and with a lot of unnecessary information. These results include useful information for the search. This must be extracted from information that is not relevant with the help of agents, data mining technology and other Web 3.0 generation technologies, while security algorithms prevent users from obtaining information that they do not have access to. (Thuraisingham, 2002, p.12-14).

The figure below describes the evolution of the Internet starting with Web 1.0 (Document Web), and the transition from Web 2.0 (Social Web) to Web 3.0 (Semantic Web). 
Figure 1 - The evolution of the Internet

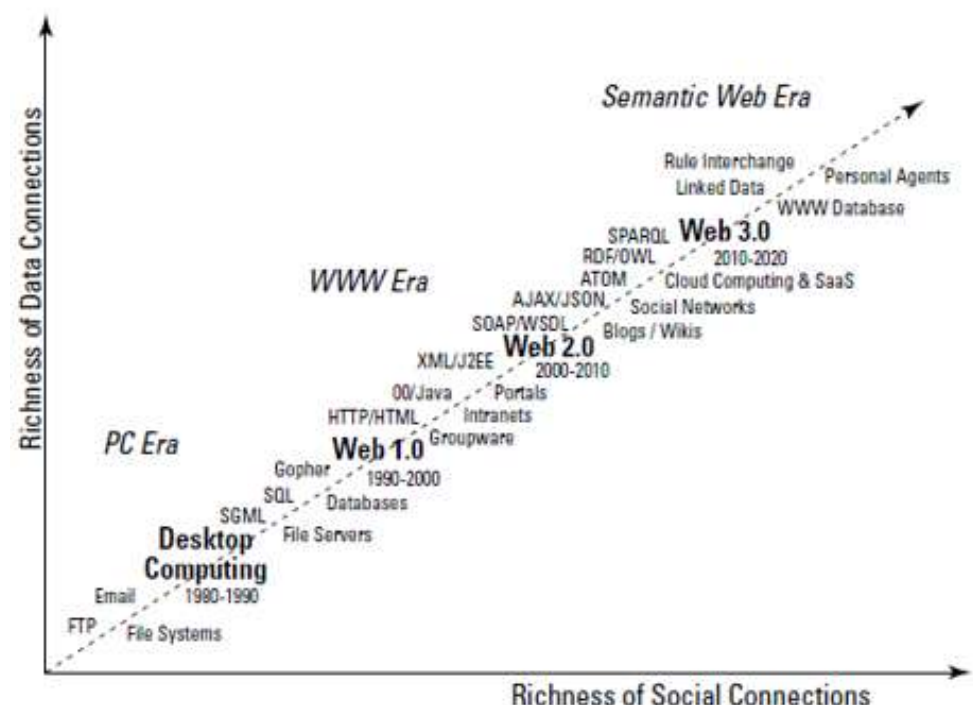

Source: Pollock, 2009, p.10

Cloud computing technology is a virtual environment, characteristic of the Web 3.0 generation, where the user needs a computer or a smartphone to access stored information anytime and anywhere (Bhure, Bansod, 2014). Hurwitz, Kaufman and Halper (2012, p.6) mentioned that, through cloud computing technology, companies have the opportunity to offer consumers a number of applications, storage spaces and a variety of development platforms. This new technology emerged as a result of identifying a new need on the market, namely to store a large amount of information in a very short time. The existence of a large amount of data in the online environment has led companies to identify the most effective solutions that can help them quickly store the data they have. (Greavu-Șerban, 2015).

\section{The Impact of Disruptive Technologies on the Economy}

An important aspect that we wanted to study refers to the impact that disruptive technologies (mobile Internet, automation of knowledge work, Internet of Things, cloud technology, advanced robotics, autonomous and near-autonomous vehicles, next generation genomics) can have on developed countries, on the one hand, and on developing countries, on the other. The table below shows a forecasted distribution of the likely impact on the economies of developed and developing countries with respect to sized applications (\% likely impact on the economy with respect to sized applications).

If we study the impact that the evolution of mobile internet will have on various markets, it can be seen that in developed countries it will contribute to increasing employee productivity, while in developing countries there will be an increase in the number of mobile telephone users. The development of "Automation of knowledge work" technologies will increase labour productivity in developed countries, and will generate an increase in knowledge workers in developing countries (mckinsey.com).

The impact of Internet of Things (IOT) technologies can be seen to be greater in developed countries than in developing ones. In the first category, new technologies will generate the 
development of applications based on advanced infrastructure technologies. In developing countries, the degree of applicability will spread rapidly, but the degree of acceptance will be much lower, increasing progressively over the years. In terms of cloud technologies, an increase in new users living in developing countries is expected. For advanced robotics technologies, their use is expected to achieve quite high savings due to process automation in developed countries, while in developing countries a lower share of these savings is expected.

Table 1 - Possible impact of disruptive technologies on developed and developing countries

\begin{tabular}{|l|c|c|}
\hline \multicolumn{1}{|c|}{ Technologies } & Developed & Developing \\
\hline Mobile Internet & $50 \%$ & $50 \%$ \\
\hline Automation of knowledge work & $80 \%$ & $20 \%$ \\
\hline The Internet of Things & $70 \%$ & $30 \%$ \\
\hline Cloud technology & $30 \%$ & $70 \%$ \\
\hline Advanced robotics & $80 \%$ & $20 \%$ \\
\hline Autonomous and near - autonomous vehicles & $80 \%$ & $20 \%$ \\
\hline Next generation genomics & $80 \%$ & $20 \%$ \\
\hline
\end{tabular}

Source: Adapted after: mckinsey.com

Other market studies (mckinsey.com) have shown the impact that the use of new disruptive technologies could have by 2025 on various areas of activity. The results showed how these applications can affect the lives of individuals, organisations, and economic activity in countries. Mobile Internet, cloud technology and next-generation genomics can bring a number of advantages to companies that plan to launch new products on the market and operate in various markets. Disruptive technologies can also affect the way employees work and the organisational structure of companies. With the automation of certain systems, some employees may lose their jobs while specialised staff (with important knowledge in the field) can improve its skills, as these technologies have the ability to increase labour productivity.

Disruptive technologies can also improve the economic activity in countries. For example, robotics can increase productivity as well as the development of the manufacturing sector. Applications based on these technologies can help countries better manage their resources. An analysis in terms of technologies based on advanced robotics reveals that organisations that will adopt such applications in the future will benefit from an increase in labour productivity, an increase in the speed of execution and a more streamlined working time. It should be noted that they will require specialised staff with knowledge in the field. That is why there is an increased likelihood that there will be a need for staff specialising in different fields of activity in the coming years. 
INTERNATIONAL JOURNAL OF ACADEMIC RESEARCH IN BUSINESS AND SOCIAL SCIENCES Vol. 10, No. 6, June, 2020, E-ISSN: 2222-6990 @ 2020 HRMARS

Table 2 - Forecasts on the impact of disruptive technologies on the activity of companies by 2025

\begin{tabular}{|l|c|c|c|l|}
\hline & $\begin{array}{c}\text { Creates } \\
\text { Changes nature } \\
\text { of work }\end{array}$ & $\begin{array}{c}\text { Droducts } \\
\text { and } \\
\text { services }\end{array}$ & $\begin{array}{c}\text { Drives } \\
\text { economic } \\
\text { growth or } \\
\text { productivity }\end{array}$ & Affects employment \\
\hline Mobile Internet & Secondary & Primary & Primary & $\begin{array}{l}\text { Other Potential } \\
\text { impact }\end{array}$ \\
\hline $\begin{array}{l}\text { Automation of } \\
\text { knowledge work }\end{array}$ & Primary & Secondary & Primary & Secondary \\
\hline The Internet of Things & $\begin{array}{r}\text { Other Potential } \\
\text { impact }\end{array}$ & Primary & Primary & $\begin{array}{l}\text { Other Potential } \\
\text { impact }\end{array}$ \\
\hline Cloud technology & $\begin{array}{r}\text { Other Potential } \\
\text { impact }\end{array}$ & Primary & Primary & $\begin{array}{l}\text { Other Potential } \\
\text { impact }\end{array}$ \\
\hline Advanced robotics & Primary & Primary & Primary & Secondary \\
\hline $\begin{array}{l}\text { Autonomous and near }- \\
\text { autonomous vechiles }\end{array}$ & Secondary & Primary & Secondary & Secondary \\
\hline $\begin{array}{l}\text { Next generation } \\
\text { genomics }\end{array}$ & $\begin{array}{r}\text { Other Potential } \\
\text { impact }\end{array}$ & Primary & Secondary & $\begin{array}{l}\text { Other Potential } \\
\text { impact }\end{array}$ \\
\hline
\end{tabular}

Source: Adapted after: mckinsey.com

In the next part of the paper, we conducted a quantitative study through which we aimed to identify the perception of employees from various fields of activity regarding the cloud services they use in the organisations in which they work.

\section{Methodology research and key findings}

Cloud computing technology has started to be used more and more often by many organisations in various fields of activity out of the desire to reduce working time, to improve employee efficiency, but also to share various documents with each other even if they are at a distance. The purpose of this quantitative research is to identify the perception of employees in various fields of activity regarding the cloud services that they use in the companies in which they work. In order to carry out this study, data were collected from both secondary and primary sources. The research method chosen was the survey, and the tool used to collect the data was the ad hoc online survey. The method used was snowball sampling. The study was conducted between 2017 and 2019 on a sample of 315 respondents. Data collection was done using a questionnaire that was posted on an online platform.

After analysing the results, it was noted that 8 out of 10 employees participating in the study agree with the statements that cloud services allow uniform access to stored data, and have the ability to adapt to current requirements by performing a real-time analysis of storage capacity, storage power, etc. 
INTERNATIONAL JOURNAL OF ACADEMIC RESEARCH IN BUSINESS AND SOCIAL SCIENCES Vol. 10, No. 6, June, 2020, E-ISSN: 2222-6990 @ 2020 HRMARS

Figure 2 - Respondents' perception on the image of the cloud services they use in the companies in which they work

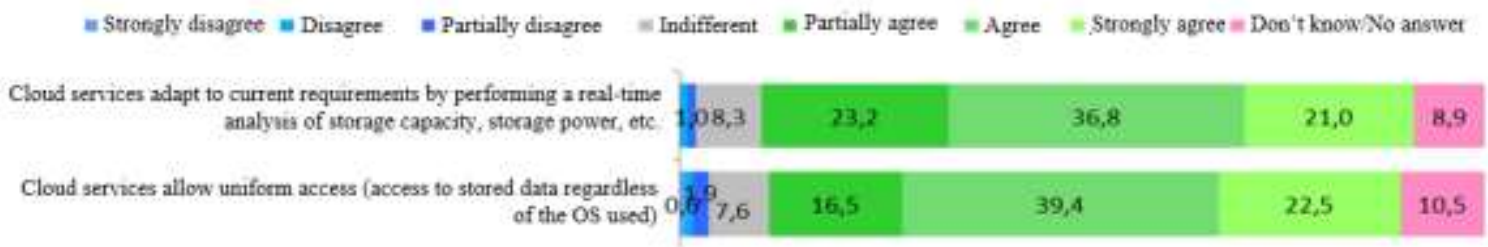

Source: Statistical survey conducted by the author

Most of the respondents (91.4\%) are receptive to change or novelty in general. Moreover, for 8 out of 10 employees, the company in which they work encourages them professionally to integrate cloud services in their daily activities, and in case of problems regarding their use, the people in charge of maintaining the cloud services send customised solutions to the employees (74.9\%). The cloud service provider understands the specific needs of employees (58.4\%), and provides them with support on solving the problems encountered (63.8\%).

Figure 3 - Respondents' perception on their understanding of the cloud services they use in the companies in which they work

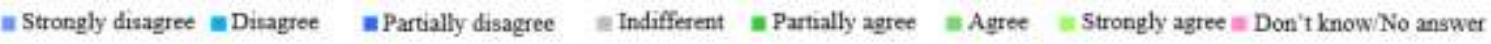

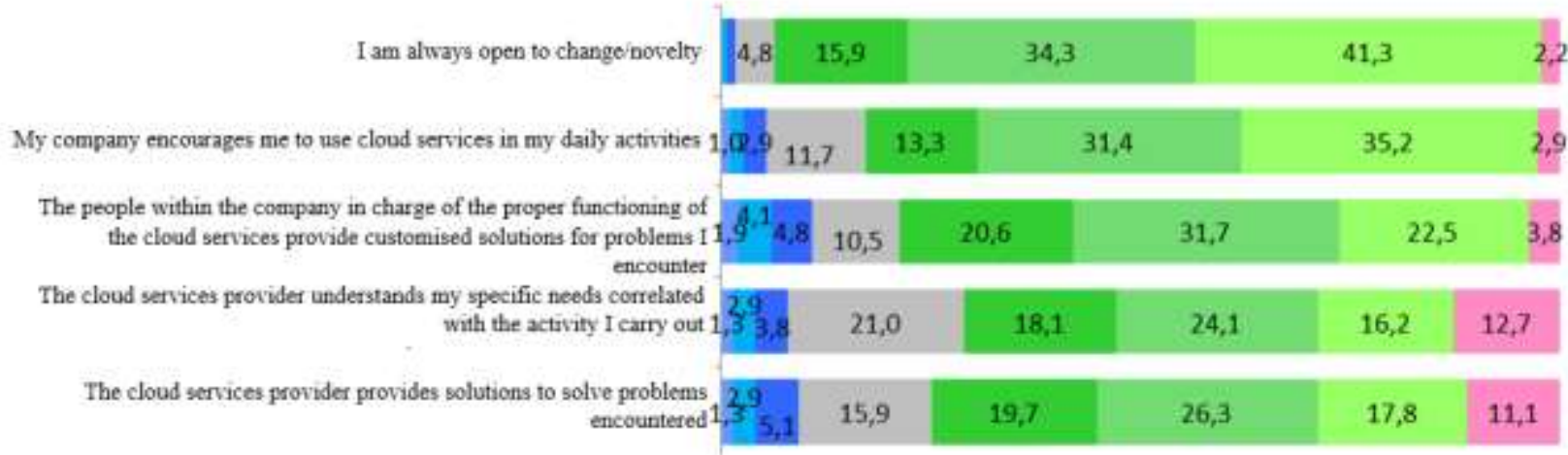

Source: Statistical survey conducted by the author

Overall, the vast majority of employees who participated in the study (88.6\%) agree that the cloud services they use within the company in which they work have a very good quality.

Figure 4 - Respondents' perception on the quality of cloud services used in the companies in which they work

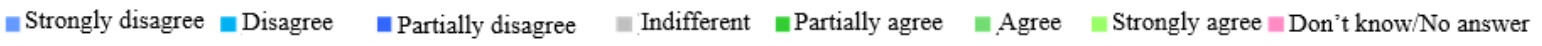

\begin{tabular}{l|l|l|l|l} 
The quality of cloud services I use within the company is very good $1,96,0$ & 42,9 & 28,6 \\
\hline
\end{tabular}

Source: Statistical survey conducted by the author

In general, most of the employees (88.3\%) say they are satisfied with the cloud services they use within the company in which they work. 
INTERNATIONAL JOURNAL OF ACADEMIC RESEARCH IN BUSINESS AND SOCIAL SCIENCES

Vol. 10, No. 6, June, 2020, E-ISSN: 2222-6990 @ 2020 HRMARS

Figure 5 - Satisfaction felt by respondents with respect to the cloud services they use in the companies in which they work

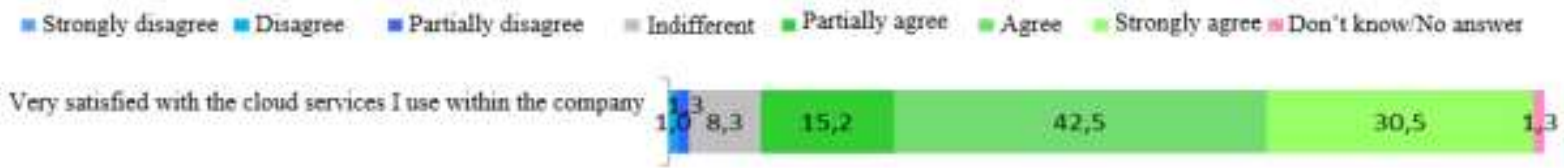

Source: Statistical survey conducted by the author

In terms of the characteristics of the interviewees, $44.8 \%$ of the people participating in this study work in companies that operate in IT. $4.3 \%$ of the respondents work in companies that operate in marketing/advertising/market research, while $6.7 \%$ of employees work in companies that operate in trade, and $5.1 \%$ in communications. The other companies recorded percentages lower than $5 \%$.

Figure 6 - Areas of activity of the companies in which the respondents work

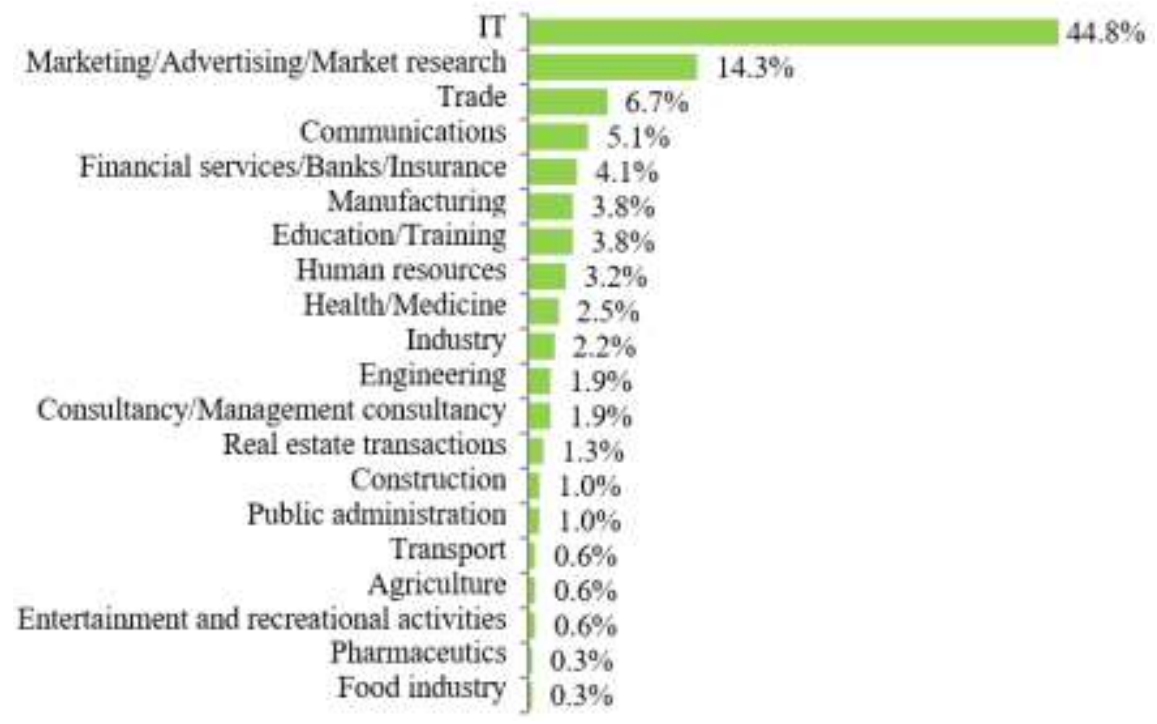

Source: Statistical survey conducted by the author

In terms of department in which they work, $27.3 \%$ of the people participating in the study work in the marketing department of the company, $22.2 \%$ in the IT department, and $13.3 \%$ in the human resources department. About 1 in 10 employees works in the sales department, 8.9\% in manufacturing, and $5.4 \%$ in the management department. The other respondents work in departments that have scores lower than $5 \%$. Analysing from the perspective of demographic characteristics, most of the respondents who participated in this research are women, aged between 18-29, university graduates. 
INTERNATIONAL JOURNAL OF ACADEMIC RESEARCH IN BUSINESS AND SOCIAL SCIENCES Vol. 10, No. 6, June, 2020, E-ISSN: 2222-6990 @ 2020 HRMARS

Figure 7 - Departments in which respondents work

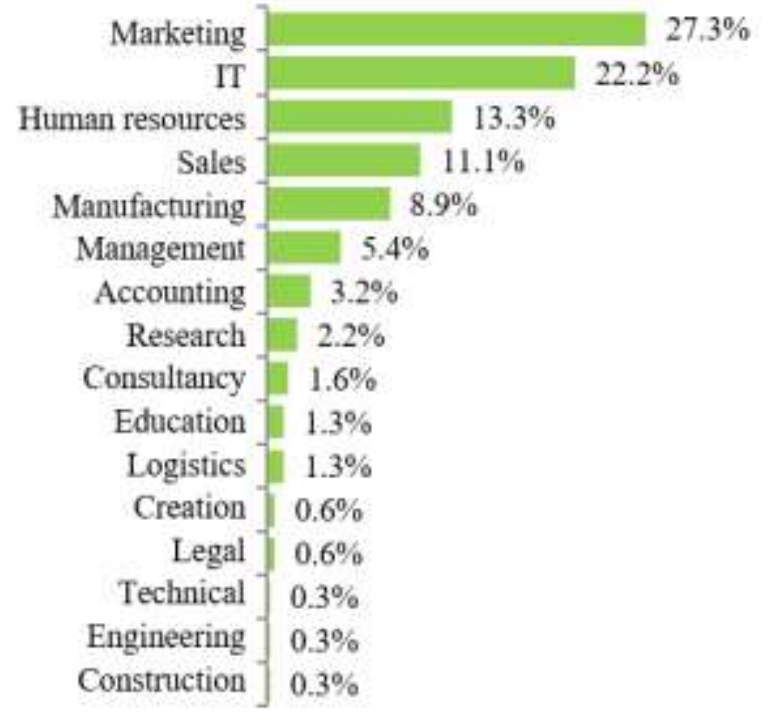

Source: Statistical survey conducted by the author

In terms of the characteristics of the companies in which they work, employees are classified as follows: 1 in 3 people participating in the study work in a company with over 1,000 employees, while 2 in 10 respondents work in a company which has between 50 and 249 employees. 13.7\% of employees work in a company that has between 1 and 9 employees, and 19\% work in companies with 10-49 employees. About 1 in 10 respondents works in a company with 250 to 1,000 employees.

Figure 8 - Number of employees of the companies in which the respondents work

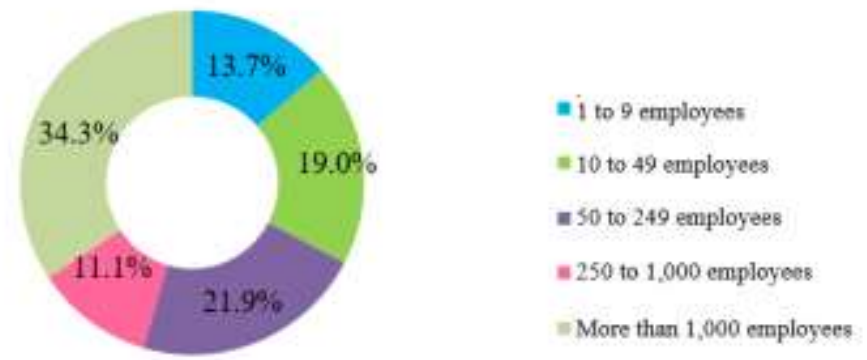

Source: Statistical survey conducted by the author

If we analyse the respondents who participated in the study according to the nature of the capital of the company in which they work, we can mention the following: almost half of the respondents work in a multinational corporation, while 1 in 3 employees works in a private company with $100 \%$ Romanian capital. $15.6 \%$ of the participants in the study work in a private company with mixed capital, Romanian and foreign, and $4.8 \%$ of employees work in a state-owned company. 
INTERNATIONAL JOURNAL OF ACADEMIC RESEARCH IN BUSINESS AND SOCIAL SCIENCES

Vol. 10, No. 6, June, 2020, E-ISSN: 2222-6990 @ 2020 HRMARS

Figure 9 - Classification of companies in which respondents work according to the nature of capital
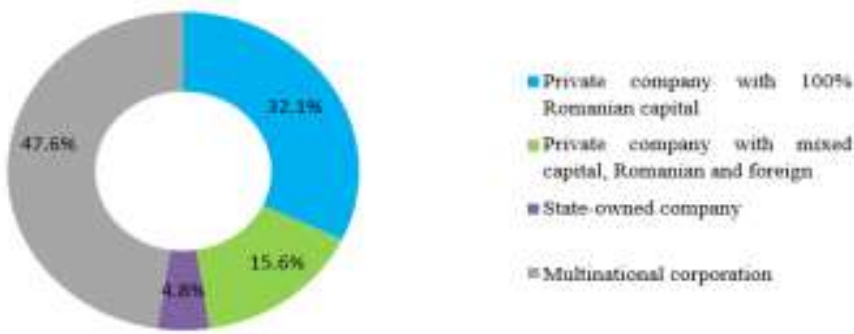

Source: Statistical survey conducted by the author

Regarding the turnover of the company in which the employees work, 6 out of 10 work in companies that have a turnover of more than EUR 1,000,000. Moreover, $11.7 \%$ of employees work in companies with a turnover between EUR 100,000-499,000, while $8.6 \%$ of all participants in the study work in companies with a turnover of less than EUR 50,000. Employees coming from companies with a turnover between EUR $50,000-99,000$ account for $8.9 \%$ of the respondents, and $7.9 \%$ of all the employees participating in the study claim that they work in companies with a turnover between EUR $500,000-1,000,000$.

Figure 10-Turnover of the companies in which the respondents work

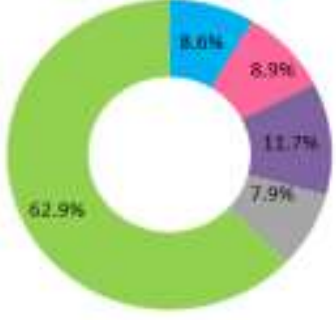

- Lews than EUR 50,000

=EUR 50,000 - 99,999

DEUR $100,000-499,999$

DEUR $500,000-1,000,000$

"More than EUR 1,000,000

Source: Statistical survey conducted by the author

In terms of the registered office of the company in which the respondents work, 7 out of 8 work for a company that has its registered office in Bucharest, with the others working for companies with their registered office in another city/town in the country.

Figure 11 - The location of the companies' registered office

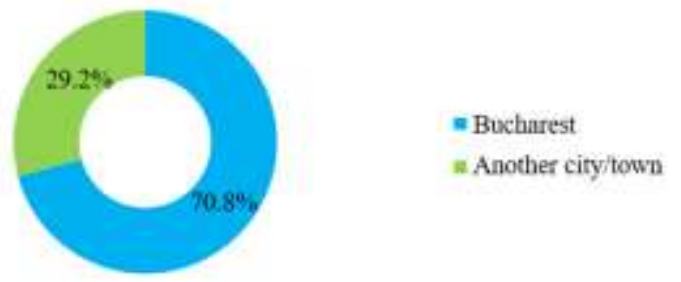

Source: Statistical survey conducted by the author

\section{Research limitations}

A first limitation of this study refers to the small number of respondents based on which this study was conducted. In the future, we believe that more detailed studies should be carried out that 
will give us a complete picture of the analysed subject. In addition, the sample consisted mainly of people with graduate and postgraduate studies, who hold management positions or are employed in large companies. In the corporate workplace, cloud services have strong visibility among employees and executives, because they are encouraged to use these services to streamline their work. As such, by frequently using cloud services, they have the knowledge to easily recognise them. In the future, we believe that it is necessary to carry out these studies also among people who do not hold management positions, but who use cloud services on a daily basis in their work. Thus, we will be able to have an overview on the analysed subject, and we will be able to better understand the way in which cloud services have the ability to influence the activity of employees in Romania.

Another limitation in this study refers to the small number of variables that were considered in the analysis. We believe that in the future other variables should be taken into account that can explain the analysed subject in more detail. As can be seen from the data analysis, the results of the study can be considered as reference directions for a variety of types of future research, which may focus, for example, on the integration of cloud services in a specific field, or the identification of segments of cloud users, or, conversely, on investigating the communication methods used by cloud service providers.

\section{Conclusions}

Cloud computing technology has started to be used more and more in companies which use it to streamline employees' working hours, but also to facilitate work processes. In the study carried out in this paper, we analysed the employees' perception on the cloud services that they use within the company in which they work. Following the analysis, it was noted that the respondents believe that these services adapt to their current requirements, through real-time analysis of storage capacity, processing power, etc. In addition, they provide uniform access to data for everyone, which means that everyone can access the stored data regardless of the used operating system. The interviewees mentioned that their organisations constantly encourage them to use cloud services in their daily work, providing them with all the infrastructure they need. In addition, if they encounter various problems, specialised staff provides them with customised solutions according to their requests. Regarding the cloud service providers used, respondents mentioned that these understand their needs and provide them with quick solutions to the problems they face. The interviewees said they were satisfied with the cloud services they use within the company at this time, and consider the quality of services to be quite high.

In view of the above, we believe that the information provided is intended to give a much clearer picture of how cloud services should be implemented and used in companies. In addition, the information presented in the quantitative study illustrates the employees' perception on these technologies as well as how they should be provided within companies to improve the satisfaction of individuals.

\section{References}

Bhure, G. C., Bansod, S. M. (2014), E-learning Using Cloud Computing, International Journal of Information and Computation Technology, Vol. 4, Nr. 1, pp. 41-46;

Greavu-Șerban, V. (2015), Cercetare avansată postoctorală: CLOUD COMPUTING CARACTERISTICI ȘI MODELE, București: ASE,http://excelenta.ase.ro/Media/Default/Page/greavuserbanv.pdf;

Hurwitz, J., Kaufman, M., Halper, F. (2012), Cloud Services for Dummies, Hoboken: John Wiley \& Sons; 
INTERNATIONAL JOURNAL OF ACADEMIC RESEARCH IN BUSINESS AND SOCIAL SCIENCES

Vol. 10, No. 6, June, 2020, E-ISSN: 2222-6990 @ 2020 HRMARS

O'Reilly, T. (2009), What is Web 2.0, O'Reilly Media;

Passin, T. B. (2004), Explorer's Guide to the Semantic Web, USA: MANNING;

Pollock, J. T. (2009), Semantic Web For Dummies, Hoboken: Willey Publishing;

Tatnall, A. (2010), Web Technologies: Concepts, Methodologies, Tools, and Applications, Hershey: Information Science Reference;

Thuraisingham, B. (2002), XML databases and the semantic web, Florida: CRC Press LLC. 